\title{
Active learning reflective review: Key to re-engage students back in the classroom after a pandemic hiatus
}

Rubilyn, Gitgano L. $\square$

University of the Visayas, Philippines (rubgit@gmail.com)

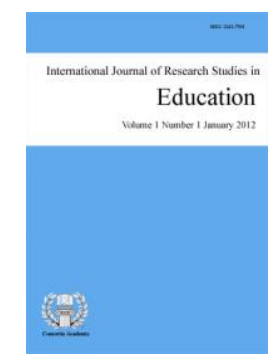

Accepted: 20 February 2022

ISSN: 2243-7703 Online ISSN: 2243-7711

OPEN ACCESS

\section{Abstract}

The COVID-19 pandemic has affected almost every aspect of society and the education sector is no exception. As a result of the pandemic, schools switched entirely to online, remote, or modular instruction. As a result, teachers being the frontline in the educational field have to deal with insurmountable pedagogical challenges while fighting pandemic paranoia in their own households. Around the world, countries are reverting to partial or full in-person learning. Having been learning remotely for nearly two years, children whose health and well-being are at risk because of the pandemic. This calls for an innovative and creative approach, and thus requires schools to modify their instructional practices and models. Is the world ready to face this challenge? This review provides an overview of the active learning model with emphasis on (1) Theoretical Framework of Active Learning (2) Benefits and Challenges as well as the implementation process (3) Implications to Practice. Analysis showed that active learning is a potential approach to reinvigorate and motivate students back to in-person learning. As schools around the world return to in-person instruction, this paper discusses the many reasons for implementing Active Learning. The author conveys the multiple benefits of actively involving students in the learning process, in contrast to delivering the content to students through direct teaching.

Keywords: active learning, pandemic, re-engage, instruction, innovative, approach 


\section{Active learning reflective review: Key to re-engage students back in the classroom after a pandemic hiatus}

\section{Introduction}

Countries around the world are transitioning back to partial if not full in-person learning. With the persistent global pandemic, it became necessary for schools to tailor their instructional practices and models to the ever-changing needs of students who have been learning remotely for almost two years and whose mental and socio-emotional wellbeing is at risk. The big question is are we ready to face this challenge? What can we do to recapture the minds, reignite the interest, and re enhance the motivation of our students back to learning whose motivation, mental and socio-emotional wellbeing are affected if not hardly hit by the COVID 19 pandemic?

There are many possible answers to this timeless question. One answer lies in the use of active learning strategies in the classroom that are discussed in this paper. In the wake of the COVID-19 pandemic, educators have been looking for new ways to engage students. As schools and teachers adapted to new technologies, students were experiencing psychological effects such as isolation, restlessness, and inattention resulting from quarantine and remote. Pandemics have demonstrated that traditional practices need to be restructured.

The purpose of this paper is to present a convincing case for integrating active learning techniques into virtually any learning environment with students of any age and in virtually any learning environment. The paper further aims to provide educators, curriculum developers and administrators out there who are faced with the dilemma of how to inculturate students back into the classroom mode for the many reasons of employing the Active Learning model. It is with pervent hope that this paper can guide stakeholders in future decision making and in not only shifting instructional paradigm from being teacher dominated to student led but also in reviving students interest in going back to in person instruction.

\section{Active Learning Framework}

Activating the brain does not seem like an easy concept to understand. Its roots are found in constructivist learning theories. Building new knowledge in relation to existing knowledge is the basis for constructivism, which has become a leading learning paradigm. In this theory, learning is emphasized through understanding rather than memorization. There are many different kinds of learning, including cognitive constructivism (individual learning), social co-construction of knowledge (social constructivism), or a hybrid of the two. However, constructivism is a theory of learning, not a theory of teaching. This makes it difficult to specify factors associated with effective constructivist teaching. Instructional strategies that promote deep understanding can and have been formulated using constructivism.

An instructional approach called active learning, for example, aims to enable constructivist learning by emphasizing the self-construction of knowledge by students as well as the responsibility of students for their own learning. This implies that students learn most effectively when they are actively involved in learning activities instead of passively receiving information, which is the hallmark of active learning. Furthermore, active learning involves students working in groups and discussing and reflecting on concepts, problems, and issues in a social context. This inherently makes learning a social process, as student and teacher work together to build knowledge. Since knowledge cannot be directly imparted to students, the purpose of teaching is to create experiences that facilitate the acquisition of knowledge. Contrary to traditional methods that believe in providing information to students directly, constructivism argues that this cannot happen. Students can only gain knowledge through their own experiences. Teaching, therefore, should focus on designing such learning experiences. 
Active learning reflective review: Key to re-engage students back in the classroom after a pandemic hiatus

In active learning, students are actively involved in their own learning when they are in class with their instructors. As part of this type of teaching strategy, students may cooperate during class, but they may also be required to work independently and reflect. During these activities, students can write journals, take part in group discussions, and solve problems, as well as engage in longer, more in-depth frameworks like case studies, role plays, and structured teamwork. There are growing body of research demonstrating the effectiveness of active learning. By actively involving students in activities, you can increase their ability to think critically, increase their ability to retain and transfer new information, increase their motivation, increase their interpersonal skills, and decrease their course failures (Prince, 2004).

An analysis of the National Survey of Student Engagement (NSSE) examined student engagement activities at 1600 colleges and universities since 2000. (Shinde, 2010). Based on their findings, students' achievement and personal development are positively shaped by active learning experiences that are hands-on, collaborative, and integrative (Kuh, O'Donnell, \& Schneider, 2017). Also, Freeman et al. (2014) have conducted a thorough meta-analysis of STEM education studies that concluded active learning is more effective than didactic teaching, particularly in classes with less than 50 students. According to their analysis, students in courses with no active learning were 1.5 times more likely to fail the course than those with active learning. Furthermore, research has shown that active learning and emotional states are interconnected. As a result, active learners need to pay more attention and retain more memory (Owens, Sadler, Barlow, \& Smith-Walters, 2017); this, in turn, impacts motivation at the macro level (Cavenagh, 2016).

\section{Active Learning Implementation}

The Center for Educational Innovation of the University of Minnesota outlined four basic steps in the successful implementation of Active Learning. The first element is choosing meaningful activities or questions. To this end three things need to be thought of; instructional goal and objective, misconception and the bridge to practice. Reflecting on these three questions such as what are the most important things students should learn from this class session? What misconceptions or difficulties do students commonly have as it relates to this content and What kind of practice can students do that will help them prepare for an upcoming assignment or assessment? Are vital elements in ensuring meaningful active learning engagement. Recognizing the answers to these three questions provides students opportunities to meaningfully engage with the material.

Active learning should also be implemented with an understanding of the rationale or purpose behind the activity. It is always helpful to know the rationale or purpose behind the activity at the beginning of the semester and during the class orientation. It includes telling the students what kind of activities they are expected to engage in and why you're having them engaged in activities during class. More importantly, developing a facilitation protocol is essential in the successful implementation of active learning. Facilitating active learning is influenced by several factors like the number of students, the chemistry of students in class, the class arrangement, time available and the type of activity you are planning to use. It is always a good practice to give students a short period of time to think on their own and then have them work in pairs or small groups. Also, part of this facilitation skill is to keep students on task by making them accountable to their own and letting them know the expectation when they reconvene as a whole class. By doing so students tend to stay focus knowing that anytime they can be called to share out. Closure and summary at the end of the activity is also an essential part of facilitation. This means wrapping up the salient points of the lesson which can be done by asking a group to share their reasoning or asking others who may have other or opposing views. If misconception is eminent then this is the time to address misconception. Lastly, an integral part of the facilitation is the consistent use of active learning in the classroom. This way you as an instructor can establish the routine and expectations when engaging in active learning making the process more familiar to students. By doing so actively engaging in the activities becomes a normal process for students.

Observe, gather, and record feedback is the fourth element to consider in the successful implementation of active learning. It is helpful to collect feedback from students about how activities go and how they feel and find 
them. You should save space in your notes, either paper or electronic, to record your observations after an activity. You can use this feedback to emphasize the benefits of active learning to a reluctant group of students to encourage them to buy into the idea.

\section{Active Learning: Reflection of Practice}

In order for students to engage in positive learning experiences, educators have a powerful influence (Horsfall et al., 2012). The teacher has a responsibility to create a learning environment that's engaging and focused on the student's needs, as Johnson-Farmer and Frenn (2009) state. Horsefall et al. (2012) reinforce this message by stating that student engagement in classroom activities and processes reflects the formation of teamwork and trust, which contribute to enhancing learning. It is my belief that active learning allows for all of these outcomes to occur. In reflecting on my own practice, I used Rolfe and colleagues' Framework for Reflexive Learning (2001) based on the three "What?" questions; What? So what? Now what?" questions. The question I ask myself every day in class is: What happened to me and my class today? What works and what doesn't? What does it tell/show/imply? And finally, now what's next? Is there anything I can do to improve or make it better? This practice has become an inherent part of my character. Simple questions like these help me to revisit and clarify my practice to make it better for the next time.

After teaching for over twenty years and engaging in active learning activities, I realized the importance of putting the responsibility of learning the content on students instead of taking on the burden of delivering it. As a result, I have outlined some important learning below, along with suggestions for others who might consider Active Learning as a model. As an educator, I spent most of the first few years of my career working hard. I spend a lot of time preparing lecture notes and chart papers for my discussions while learning the content. As soon as I gained sufficient knowledge of the material, I was offered the opportunity to work abroad. Days, weeks, months had passed, and I was still struggling. Not only does language/accent pose a challenge to New York City students, but their attention spans are so short that a ten-minute lecture may be too overwhelming to keep them focused. Out of the trainings, professional development and trial and error I explored several ways to engage my students and the so called "Learning by Doing" stood out and has become my guiding principle.

When I shift my instructional practice from teacher-centered to learner-centered, it has become more challenging to plan and organize my lessons, and most importantly, to convince my students that this is a better way to learn. In the middle of a semester, introducing a new teaching approach seems late, but I have to adjust otherwise the whole semester is a waste of time. In addition, students ask, why do we do this? Shouldn't you be teaching us all these things? When I first heard this question, I didn't know how to answer. However, as I continue to seek out what I believe is best for my students, Active Learning has become my mantra to teach. What have I learned from this experience? This experience has taught me to incorporate active learning and group work as early as possible. Employing active learning involves great risk--the risks that students will not participate especially in a population of under credited over age students that I am serving. Added to this risk is the inconsistent approach to teaching across content where mostly relies on lecture, direct instruction and unstructured computer-based instruction. It is necessary first to identify and understand common barriers to instructional shift, including the powerful influence of educational tradition.

Yet understanding what and why you are doing things a certain way makes it easier to convey the message to the students. Students question all the time why are they doing this only in my classroom? How did I overcome all these? Careful and thoughtful planning is the key. Communicating all these from the beginning of the course and consistently using an active learning approach drives the success of the model. A new strategy is not going to be an easy sell if it is introduced in the middle of the semester. You should start as you intend to continue. Let the students know what you expect of them and get them excited about it as soon as possible. This being said, start incorporating active learning strategies into your courses during the first week of the semester. As a result, you can establish the class tone, expectations, and routine, and enforce the same practice throughout the entire semester. 
Active learning reflective review: Key to re-engage students back in the classroom after a pandemic hiatus

Another significant learning, I have during the course of implementing active learning in my practice is the value of facilitation skills. Facilitation skill is necessary to ensure that students are productively engaged on task and reflectively thinking about the task that they are doing. Oftentimes, the success of actively engaging students lies in how the activity is being facilitated. What I found worked well with my students across different demographics and different learning styles is to always begin any active learning activity with an individual brainstorming/thinking time that serves as the springboard of the content and/or activity you are delving into. This way students can tune their minds and mentally prepare themselves for the type of work they will be tackling before asking them to turn to their partners or group.

In terms of facilitation, ensuring students remain on task is also crucial to the success of active learning. Clearly communicating expectations both orally and in writing is essential. Modeling the group task to students must be accompanied by a clear written directive in order to save time. Oftentimes, I hear myself repeating over and over as soon as students work in pairs/groups independently. To address this, every active learning activity in my classroom always goes with written directives that students may refer to. This has saved a lot of my time and energy. A facilitation strategy also involves letting students know they must be ready to share and explain what they do when you visit them or when you meet them as a whole class. Holding members of the team accountable for the group's grade will encourage them to take responsibility for their own actions and learning, as well as for the team as a whole. Students will most likely fail to achieve instructional goals and deliver the expected product if expectations, elements of a task are unclear.

\section{Conclusion / Future Direction}

This paper demonstrates the need to use Active Learning in classrooms as a means of recapturing the minds, retriggering the interest, and restoring the motivation of our students whose interest, mental, and socio-emotional wellbeing, have been negatively affected by COVID 19. By incorporating Active Learning into the classroom, students are able to improve their learning skills and bring their desire to learn back after a period of hiatus. To answer the ever-increasing requests for reformulating instruction to meet the demands of time, the active learning model is obviously one, if not the best, solution.

To incorporate active learning in the teaching tradition, teachers and staff must take part if not take the lead in reforming and shifting instructional practices. Administrators, coaches and professional developers are highly recommended to explore and develop workshops and trainings that include active learning as a topic as well as methods of facilitating the active learning model. With a more in-depth understanding and with administrative support, shifting instruction from direct teaching to a student centered learning and doing approach will be feasible. Furthermore, continued research to determine the usability and effectiveness of active learning may be needed to convince and drive decisions of educators, administrators and curriculum developers in finding approaches that can enhance the interest of our students back to learning whose motivation, mental and socio-emotional wellbeing has been hardly hit by the COVID 19 pandemic.

\section{References}

Cavanagh, A. J., Aragón, O. R., Chen, X., Couch, A., Durham, F., Bobrownicki, A., Hanauer, D. I., \& Graham, M. J. (2016). Student buy-in to active learning in a college science course. CBE life sciences education, 15(4), 76. https://doi.org/10.1187/cbe.16-07-0212

Freeman, S., Eddy, S. L., McDonough, M., Smith, M. K., Okoroafor, N., Jordt, H., \& Wenderoth, M. P. (2014). Active learning increases student performance in science, engineering, and mathematics. Proceedings of the national academy of sciences, 111(23), 8410-8415.

Horsfall, J., et al. (2012). Developing a pedagogy for nursing teaching-learning. Nurse Education Today, 32(8), 930-933. https://doi.org/10.1016/j.nedt.2011.10.022

Johnson, M. (2021). Teaching excellence in the context of business and management education: Perspectives from Australian, British and Canadian universities. The International Journal of Management 
Rubilyn, G. L.

Education, 19(3), 100508.

Kuh, G. (2017). Hips at ten. Change: The Magazine of Higher Learning. Routledge.

Owens, D. C., et al. (2017). Student motivation from and resistance to active learning rooted in essential science practices. Research in Science Education, 50(1), 253-277. https://doi.org/10.1007/s11165-017-9688-1

Prince, M. (2004). Does active learning work? A review of the research. Journal of Engineering Education, 93(3), 223-231. https://doi.org/10.1002/j.2168-9830.2004.tb00809.x

Rolfe, et al. (2001). Reflective model. My.Cumbria. https://my.cumbria.ac.uk/media/MyCumbria/Documents/ReflectiveModelRolfe.pdf

Shinde, G. S. (2010). The relationship between students' responses on the national survey of student engagement (NSSE) and retention. Review of Higher Education \& Self-Learning, 3(7). 